кандидат экономических наук, доцент кафедры финансов, инвестиций и кредита Орловского государственного

аграрного университета

\section{ОЦЕНКА ВЛИЯНИЯ MEГАПРОЕКТА ТЕПР НА АГРОПРОДОВОЛЬСТВЕННЫЕ И РЕСУРСНЫЕ РЫНКИ АПК РОССИИ}

Аннотация:

В статье исследована сущность всероссийского мегапроекта Транс-Евразийский пояс «Razvitie» (TEПР), произведена оценка его влияния на аграрный сектор экономики России в целом и на развитие агропродовольственных и ресурсных рынков АПК в частности. Автор выявляет положительную динамику увеличения спроса на сельскохозяйственное сырье и продукты питания отечественного производства со стороны многомиллионного Китая и определяет относительно стабильное потребление российского продовольствия Европейским союзом. Утверждает, что формирование ТЕПР будет способствовать повышению доступности потребителей восточных и западных стран мира для представителей аграрного бизнеса России, а также росту конкурентоспособности местной сельскохозяйственной продукции на международном рынке. Кроме того, в работе представлена матрица влияния ТЕПР на агропродовольственные и ресурсные рынки АПК России. Сформулировано предложение по организации сети сельскохозяйственных маркетинговых центров по контуру Транс-Евразийского пояса, высокотехнологичная мультиинфраструктура которого будет способствовать повышению эффективности функционирования перераспределительных площадок продовольствия от организаций АПК различных форм хозяйствования в России до конечных потребителей за рубежом.

\section{Ключевые слова:}

Транс-Евразийский пояс «Razvitie», агропродовольственные рынки, сельскохозяйственное сырье, продукты питания, сельскохозяйственные маркетинговые центры, экспорт продукции АПК.
$\mathrm{PhD}$ in Economics, Associate Professor, Department of Finance, Investments and Credit, Orel State Agrarian University

\section{ASSESSING THE IMPACT OF TRANSEURASIAN CORRIDOR RAZVITIE ON AGRIFOOD AND AGRARIAN RESOURCE MARKETS IN RUSSIA}

Summary:

The study considers Russian nationwide project Transeurasian Corridor Razvitie and estimates its influence on the agrarian sector of Russian economy in general and the development of agrifood and agrarian resource markets in particular. The author identifies the positive dynamics of increasing demand for domestic agricultural raw materials and foodstuffs by multi-million China and defines a stable consumption of Russian foodstuffs by the European Union. It is argued that Transeurasian Corridor Razvitie will enhance the availability of consumers from Eastern and Western countries by Russian agrarian businessmen and increase the competitiveness of national agricultural products on the international market. Moreover, the impact matrix of the above-mentioned project in relation to agrifood and agrarian resource markets is represented. The study presents the ideas for establishing a network of agricultural marketing centers along the Transeurasian Corridor zone. Its high-tech multi-infrastructure will in crease the efficiency of redistributive platforms of agricultural raw materials and foodstuffs from Russian agrarian organizations to the ultimate consumers in foreign countries.

Keywords:

Transeurasian Corridor Razvitie, agrifood markets, agricultural raw materials, foodstuffs, agricultural marketing centers, agricultural export.

В условиях ограничения экономического сотрудничества со странами Запада Россия все более переориентируется на развитие взаимоотношений со странами Азии. В связи с этим повышается актуальность реализации проекта ТЕПР на территории Российской Федерации.

ТЕПР, или Транс-Евразийский пояс «Razvitie», «предполагает формирование на территории Сибири и Дальнего Востока важнейших составляющих нового технопромышленного и социокультурного уклада. Принципиальным элементом этого уклада являются интегральная инфраструктурная система (мультиинфраструктура). Она объединит транспорт, энергетику, телекоммуникации, транспортировку воды, нефти и газа, обеспечит создание новых отраслей промышленности и новых научно-технологических и инженерных городов вдоль БАМа и Транссиба» [1].

Одним из идеологов концепции ТЕПР является Юрий Вячеславович Громыко - директор Института опережающих исследований имени Шифферса. По его словам, Транс-Евразийский пояс «Razvitie» - это своеобразный пространственный коридор, объединяющий Европу и Азию, который одним своим фрормированием послужит механизмом стимулирования развития не только прилегающих к нему территорий и обслуживающих его отраслей в России, но и международных экономических отношений, культурных связей Европы и Азии [2, р. 13]. 
Реализация данного проекта может стать большим стимулом для развития экономики России в целом, а также для реализации потенциала отечественного АПК в частности. Среди крупных потребителей сельскохозяйственного сырья и продуктов питания стран Азии можно выделить многомиллионный Китай. Динамика потребления данной страной продовольственных товаров и сельскохозяйственного сырья, произведенных в Российской Федерации, представлена на рисунке 1.

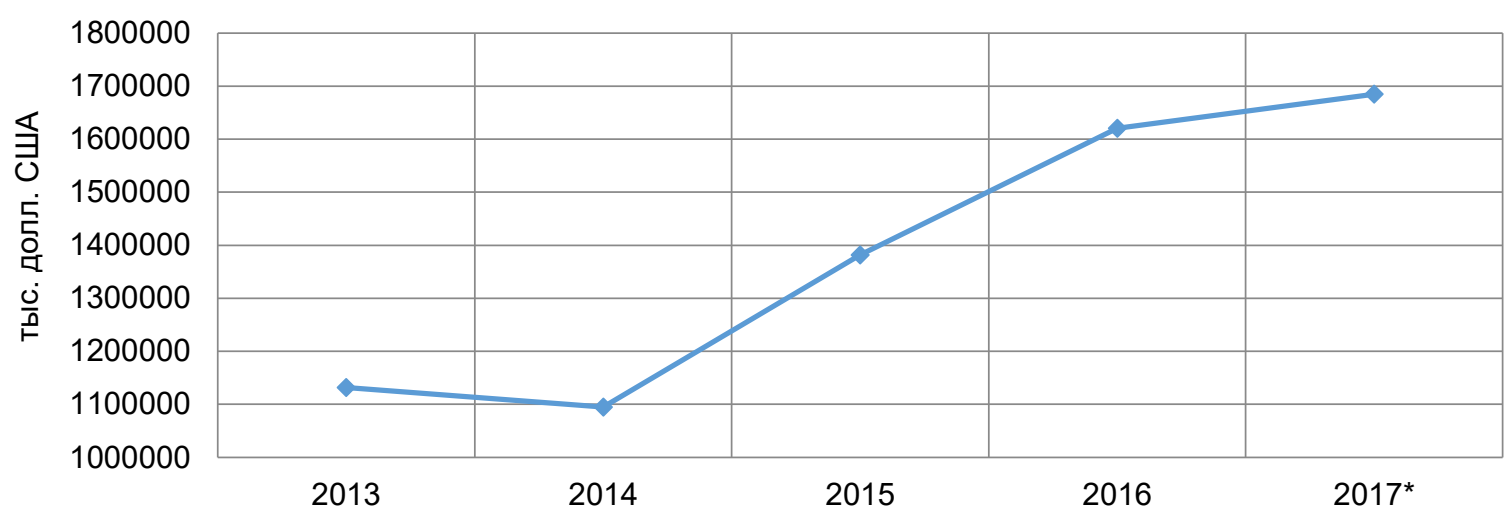

* Прогнозные данные.

Рисунок 1 - Динамика экспорта продовольственных товаров и сельскохозяйственного сырья из России в Китай с 2013 по 2017 гг., тыс. долл. США [3]

За последние пять лет российский экспорт продовольственных товаров и сельскохозяйственного сырья в Китай увеличился на 49 \%. Стабильный рост прослеживается с 2014 г. Безусловно, одной из причин такой тенденции является переориентация потока российских товаров на Восток после охлаждения внешнеполитических отношений России с Западом, отразившегося на соответствующих международных экономических связях. Ключевыми товарными группами сельскохозяйственного экспорта в Китай являются: рыбная продукция (69 \%), жиры и масла животного и растительного происхождения (11\%), масличные и прочие семена (10\%), готовые продукты из зерновых (3 \%) и корма для животных (3 \%) [4].

Вместе с тем, несмотря на снижение экономической активности России по отношению к странам Европейского союза, что подтверждается отрицательной динамикой аграрного экспорта из РФ в EC, представленной на рисунке 2, наш европейский сосед остается одним из важных потребителей сельскохозяйственного сырья и продуктов питания отечественного производства.

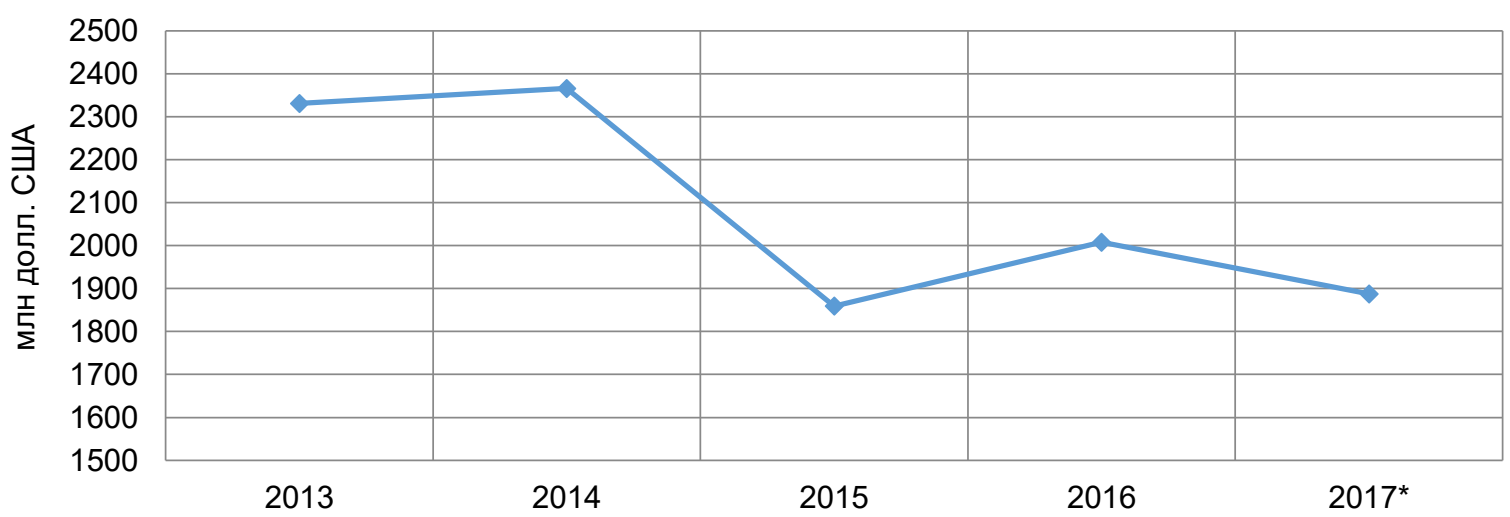

* Прогнозные данные.

Рисунок 2 - Динамика экспорта продовольственных товаров и сельскохозяйственного сырья из России в страны Европейского союза за период с 2013 по 2017 г., млн долл. США

По итогам 2016 г. отечественный аграрный экспорт в страны ЕС снизился на 13,88 \% и 15,15 \% по отношению к аналогичному показателю за 2013 и 2014 гг. соответственно. Однако если рассматривать изменение доли экспорта продовольственных товаров и сельскохозяйственного сырья, приходящейся на страны ЕС, в общей структуре российского аграрного экспорта, то снижение происходит не столь быстрыми темпами (см. таблицу 1). 
Таблица 1 - Экспорт продовольственных товаров и сельскохозяйственного сырья из России в 2013-2017 гг., млн долл. США

\begin{tabular}{|c|c|c|c|}
\hline \multirow{2}{*}{ Год } & \multirow{2}{*}{ Всего } & \multicolumn{2}{|c|}{ В страны ЕС } \\
\cline { 3 - 4 } & & млн долл. США & \% \\
\hline 2013 & 16261,7 & 2331,3 & 14,34 \\
\hline 2014 & 18981 & 2366,2 & 12,47 \\
\hline 2015 & 16215,1 & 1859,1 & 11,76 \\
\hline 2016 & 17069,7 & 2007,8 & 9,35 \\
\hline
\end{tabular}

* Прогнозные данные.

К концу 2016 г. доля экспорта сельскохозяйственного сырья и продуктов питания в Европейский союз в общем объеме российского экспорта снизилась на $2,58 \%$ и 0,71 \% в сравнении с аналогами 2013 и 2014 гг. соответственно. Показатели по итогам 2017 г., рассчитанные на основе данных за 2013-2016 гг., а также данных за I и II кварталы 2017 г. таможенной статистики внешней торговли с помощью экстраполяции, на наш взгляд, пессимистичны и могут быть увеличены под влиянием ожиданий изменения политики взаимных санкций России и ЕС.

Возвращаясь к мегапроекту ТЕПР, скажем, что в случае его полной реализации агропродовольственные рынки России получат такие преимущества, как:

1) повышение доступности потребителей сельскохозяйственного сырья и продуктов питания на Востоке (кроме многомиллионного Китая, это динамично развивающиеся страны АCEAH, прочие страны АТЭС, Индия);

2) повышение доступности западных потребителей для представителей аграрного сектора экономики Востока России;

3) появление новых организаций сельского хозяйства, а также пищевой, химической, станкостроительной промышленности и т. п.;

4) совершенствование логистического сопровождения экспорта продукции АПК на фоне развития транспортной инфрраструктуры;

5) сокращение сроков доставки сельскохозяйственного сырья и продуктов питания до потребителей за рубежом в результате ввода в эксплуатацию сверхскоростного транспорта;

6) развитие сфреры услуг, связанной с маркетинговыми исследованиями внешних рынков, таможенным администрированием экспорта продукции АПК;

7) переход сельских территорий на новый уровень развития (благодаря формированию мультиинфрраструктуры).

Указанный список преимуществ не является исчерпывающим, реализация того или иного элемента концепции ТЕПР влечет за собой целый ряд положительных эффектов для экономики аграрного сектора РФ, однако вероятна возможность и отрицательного влияния некоторых мероприятий. Более детальный результат анализа эфффектов ТЕПР для аграрного сектора России представлен в таблице 2 .

Положительное влияние всех элементов Транс-Евразийского пояса «Razvitie» так или иначе нивелирует отрицательные эффректы. В целом основным итогом реализации данного проекта становится повышение конкурентоспособности продукции отечественного АПК на международном рынке и укрепление России в качестве крупнейшего мирового поставщика продуктов питания.

Усилить преимущества ТЕПР для аграрного сектора экономики России можно было бы посредством организации по контуру зоны пояса всероссийской сети сельскохозяйственных маркетинговых центров, «основной целью функционирования которых будет содействие продвижению и сбыту сельскохозяйственного сырья и продуктов питания посредством формирования перераспределительной площадки, обеспечивающейся централизованной системой закупок и имеющей широкую специализированную сбытовую сеть» [5].

Одним из приоритетных направлений деятельности такой сети должно стать развитие экспорта продукции АПК на местах посредством, во-первых, организации или реорганизации отечественного производства продовольствия в соответствии с международными стандартами качества; во-вторых, целенаправленной высококвалифицированной работы по поиску конкретных потребителей продукции российского АПК за рубежом; в-третьих, подготовки или привлечения специалистов для реализации первых двух пунктов.

Таким образом, Транс-Евразийский пояс «Razvitie» - это проект всероссийского масштаба, нацеленный на объединение восточной и западной части РФ посредством организации интеринфраструктурного пространства нового поколения вдоль Байкало-Амурской и Транссибирской магистралей. Помимо повышения уровня экономического развития страны в целом и прилегающих к ТЕПР территорий в частности, в результате реализации данной идеи рынки стран дальнего зарубежья становятся ближе. 
Таблица 2 - Матрица влияния ТЕПР на агропродовольственные и ресурсные рынки АПК России

\begin{tabular}{|c|c|c|c|}
\hline \multirow[b]{2}{*}{ Влияние } & \multicolumn{3}{|c|}{ Элементы ТЕПР [6] } \\
\hline & $\begin{array}{c}\text { Скоростная } \\
\text { трансроссийская } \\
\text { комплексная } \\
\text { магистраль }\end{array}$ & $\begin{array}{c}\text { Экономические зоны } \\
\text { с промышленным произ- } \\
\text { водством наукоемкого } \\
\text { инновационного } \\
\text { технологического уклада }\end{array}$ & $\begin{array}{c}\text { Равнозначное экономиче- } \\
\text { ское сотрудничество } \\
\text { со странами Западной Ев- } \\
\text { ропы, Северной Америки } \\
\text { и Юго-Восточной Азии }\end{array}$ \\
\hline 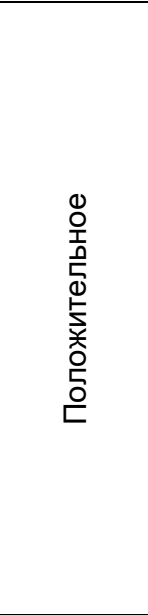 & $\begin{array}{l}\text { Скоростные железная дорога и } \\
\text { автомобильная трасса позво- } \\
\text { лят сократить время доставки } \\
\text { продуктов питания и сельско- } \\
\text { хозяйственного сырья и, соот- } \\
\text { ветственно, ускорить процесс } \\
\text { потребления продуктов с огра- } \\
\text { ниченным сроком годности. } \\
\text { Доступность сельскохозяй- } \\
\text { ственного сырья, удобрений, } \\
\text { специальной техники, консуль- } \\
\text { тантов и пр. } \\
\text { Формирование телекоммуни- } \\
\text { кационных линий связи на про- } \\
\text { тяжении всего ТЕпР способ- } \\
\text { ствует повышению уровня } \\
\text { жизни на сельских территориях }\end{array}$ & $\begin{array}{l}\text { Увеличение общего объема } \\
\text { производства продоволь- } \\
\text { ственных товаров с высокой } \\
\text { добавленной стоимостью и, } \\
\text { как следствие, переориен- } \\
\text { тация АПК с экспорта низко- } \\
\text { доходного сырья на готовую } \\
\text { продукцию. } \\
\text { Снижение издержек агро- } \\
\text { промышленного производ- } \\
\text { ства вследствие внедрения } \\
\text { инновационных технологий. } \\
\text { Интенсификация внедре- } \\
\text { ния научных разработок в } \\
\text { практическую жизнедея- } \\
\text { тельность аграриев }\end{array}$ & $\begin{array}{l}\text { Расширение географии } \\
\text { продаж сельскохозяйствен- } \\
\text { ного сырья и продуктов пи- } \\
\text { тания отечественного про- } \\
\text { изводства. } \\
\text { Стимулирование развития } \\
\text { аграрного сектора эконо- } \\
\text { мики в Сибири и на Востоке } \\
\text { России. } \\
\text { Необходимость повсемест- } \\
\text { ного внедрения междуна- } \\
\text { родных стандартов каче- } \\
\text { ства организациями всех } \\
\text { форм собственности рос- } \\
\text { сийского АПк }\end{array}$ \\
\hline 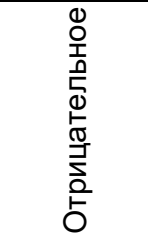 & $\begin{array}{l}\text { Изъятие части земель сельско- } \\
\text { хозяйственного назначения } \\
\text { под строительство автомо- } \\
\text { бильных дорог, железнодорож- } \\
\text { ного полотна, организацию те- } \\
\text { лекоммуникационных сетей }\end{array}$ & $\begin{array}{l}\text { Ухудшение экологической } \\
\text { ситуации в зоне ТЕПР. } \\
\text { Изменение климата }\end{array}$ & $\begin{array}{l}\text { Повышение уровня конку- } \\
\text { ренции на внутреннем рос- } \\
\text { сийском рынке продоволь- } \\
\text { ственных товаров и сель- } \\
\text { скохозяйственного сырья }\end{array}$ \\
\hline
\end{tabular}

С точки зрения влияния на агропродовольственные и ресурсные рынки АПК России формирование Транс-Евразийского пояса способствует, во-первых, повышению доступности рынков стран Азиатско-Тихоокеанского экономического сотрудничества, Индии; во-вторых, расширению предложения сельскохозяйственного сырья и продуктов питания для стран Европейского союза (посредством более активного вовлечения в борьбу за европейские рынки организаций АПК регионов Сибири и Дальнего Востока); в-третьих, повышению конкурентоспособности отечественной продукции АПК на внешних рынках за счет организации высокоэффективного инновационного производства, снижения сроков доставки, внедрения международных стандартов качества.

\section{Ссылки и примечания:}

1. Транс-Евразийский пояс «Razvitie» [Электронный ресурс] : из доклада Президента ОАО «РЖД» В.И. Якунина «Интегральный проект солидарного развития на Евро-Азиатском континенте (научно-практическая концепция)», подготовленного на базе Института социально-политических исследований РАН и презентованного на заседании президиума PAH в марте 2014 г. URL: http://www.kp-plant.ru/upload_data/2015/TEDB-Razvitie.YakuninDoklad.pdf (дата обращения: 02.01.2018).

2. Transeurasian corridor Razvitie: new dimension of cooperation / F. Bassanini, M. Baydakov, Y. Gromyko, P. Raimondi, E. Reviglio, J. Tennenbaum, V. Zyukov. Moscow, 2012. 210 p.

3. Рисунки 1, 2 и таблица 1 построены автором на основе данных Федеральной таможенной службы РФ. См.: Федеральная таможенная служба [Электронный ресурc]. URL: http://www.customs.ru (дата обращения: 02.01.2018).

4. Федеральная таможенная служба.

5. Карпова О.И. Продвижение сельскохозяйственной продукции на внутреннем и внешних рынках // Образование, наука и производство. 2016. № 4 (17). С. 28-30.

6. Материалы Института социально-политических исследований РАН [Электронный ресурс] // Материалы совместного заседания Интеграционного клуба при Председателе Совета Федерации и Научно-экспертного совета при Председателе Совета Федерации на тему «Научно-техническое сотрудничество - база евразийской экономической интеграции» (МГУ им. М.В. Ломоносова, 22 июня 2015 г.) : аналитический вестник. 2015. № 24 (577). С. 72-85. URL: http://www.council.gov.ru/media/files/41d580054e893a4758c1.pdf (дата обращения: 02.01.2018).

\section{References:}

Bassanini, F, Baydakov, M, Gromyko, Y, Raimondi, P, Reviglio, E, Tennenbaum, J \& Zyukov, V 2012, Transeurasian corridor Razvitie: new dimension of cooperation, Moscow, 210 p., (in Russian).

Karpova, OI 2016, 'Promotion of agricultural products on the domestic and foreign markets', Obrazovaniye, nauka i proizvodstvo, No. 4 (17), pp. 28-30, (in Russian). 
'Materials of the Institute for Social and Political Studies of the Russian Academy of Sciences' 2015, Materialy sovmestnogo zasedaniya Integratsionnogo kluba pri Predsedatele Soveta Federatsii i Nauchno-ekspertnogo soveta pri Predsedatele Soveta Federatsii na temu «Nauchno-tekhnicheskoye sotrudnichestvo - baza yevraziyskoy ekonomicheskoy integratsii» (MGU im. M.V. Lomonosova, 22 iyunya 2015 g.): analiticheskiy vestnik, no. 24 (577), pp. 72-85, viewed 02 January 2018, <http://www.council.gov.ru/media/files/41d580054e893a4758c1.pdf>, (in Russian).

Transeurasian Corridor Razvitie: extract from the report of the President of Joint Stock Company Russian Railways JSC V.I. Yakunin in March 2014 2018, viewed 02 January 2018, <http://www.kp-plant.ru/upload_data/2015/TEDB-Razvitie.YakuninDoklad.pdf>, (in Russian). 